\title{
MEDICATION NON-ADHERENCE AMONG ADULT PSYCHIATRIC OUT PATIENTS IN JIMMA UNIVERSITY SPECIALIZED HOSPITAL, SOUTHWEST ETHIOPIA
}

\author{
Kenfe Tesfay ${ }^{1}$, Eshetu Girma ${ }^{2}$, Alemayehu Negash ${ }^{1}$, Markos Tesfaye ${ }^{1}$, Sandra \\ Dehning $^{3}$
}

\begin{abstract}
BACKGROUND: Information on adherence of adult psychiatric patients to biological modes of treatment is scarce in Ethiopia. Knowledge on adherence is essential in terms of future prognosis, quality of life and functionality of such patients. This study was conducted to assess the magnitude and associated factors of non-adherence to medication.

METHODS: A hospital based cross-sectional study was conducted in November 2011 at the psychiatry facility of Jimma University Specialized Hospital, which provides service to more than 10 mill people. A sample of 422 adults with psychiatric illness in the follow-up outpatients was selected consecutively. Data was collected using a pre-tested questionnaire by face-to-face interview and from patient medical records. The four-item Morisky scale was used to assess degree of medication adherence. Data was analyzed using SPSS version 16 and descriptive, chi-square test and logistic regression statistical methods were used. P-Value of less than 0.05 was considered as statistically significant in the final model.

RESULTS: Out of the 422 patients, $40.3 \%$ were females and $59.7 \%$ males. The prevalence rate for nonadherence was $41.2 \%$, non-affective psychoses diagnosis contributing the highest rate (44.5\%). From the total non-adherent respondents, $78.2 \%$ attributed their non-adherence to forgetting. Irregular follow-up, poor social support and complex drug regimen were independently associated variables with nonadherence.

CONCLUSIONS: The result of the study showed that non-adherence among psychiatric patients in Southwest Ethiopia is high and revealed possible associated factors. Adherence needs integrated efforts in creating a mechanism in enhancing regular follow-up, informal social support system and ongoing awareness creation among professionals.
\end{abstract}

KEYWORDS: mental illness, non-adherence, Jimma University Specialized Hospital, Ethiopia

DOI: http://dx.doi.org/10.4314/ejhs.v23i3.5

\section{INTRODUCTION}

Non-adherence is a poly-faceted problem related with therapeutic relationship between the patient and the clinician, factors related to medications and factors related to the patients and their illness. Physicians contribute to the non-adherence because of failure to prescribe simple regimens, explain the benefits and side effects of medications and consider patients' lifestyle or medication cost involved. In addition, typical reasons for not taking medications include forgetfulness, presence of other priorities, decision to omit doses, lack of information, and emotional factors such as psychological distress. Supervision by a clinical trustee in cases of absence of insight on the patient's behalf is a significant factor for adherence as well (1-3). Non-adherence to

\footnotetext{
${ }^{1}$ Department of Psychiatry, Jimma University, Jimma, Ethiopia

${ }^{2}$ Department of Health Education \& Behavioral Sciences, Jimma University, Ethiopia

${ }^{3}$ Department of Psychiatry and Psychotherapy, Ludwig-Maximilians-University, Munich, Germany

Corresponding Author: Kenfe Tesfay, Email: kinfetesfay@gmail.com
} 
psychiatric treatment undermines treatment effectiveness, increases risk of relapse and leads to poorer outcomes $(3,4)$. Psycho education programs, family therapy and community-based interventions have been used successfully to improve adherence (4).

A systematic review of studies in USA found out that non-adherence was $41.2 \%$. The same review showed that poor insight, negative attitude or subjective response towards medication, previous non-adherence, substance abuse, shorter duration of illness, inadequate discharge planning or aftercare environment, and poorer therapeutic alliance were factors associated with nonadherence to medication (5). A study on psychotropic medications adherence reported a high frequency of non-adherence with all the five classes of psychotropic medication (antipsychotics, sedative-hypnotics, anxiolytics, mood stabilizers and antidepressants). In that study, forgetting was the main reported reason for non-adherence (6).

A study in India showed that the most common reasons for poor medication adherence were financial problems $(41 \%)$, long distance to facilities (35\%), improvement in symptoms (28\%) and other causes like side-effect, lack of caregiver, lack of insight about the illness, and nature of job (7). Another study done at a Tertiary Care Hospital in Pakistan revealed that the prevalence of non-adherence was around 39\% and the most prevalent reasons for non-adherence included sedation $(30 \%)$, medication cost $(22 \%)$, forgetting to take medication $(36 \%)$, failure of the physicians to explain timing and dose $(92 \%)$ or benefit of medication $(76 \%)$, the belief expressed as: 'I thought I am better now and do not need to take medication' (32\%) and patients' perception as 'treatment was of little benefit' $(30 \%)$. Females were more adherent to medication than males were in the Pakistan study (8).

A study from a Nigerian psychiatric unit examined 3 months post-discharge treatment and reported that $50.6 \%$ patients were adherent with appointments while $57.4 \%$ were non-adherent to medication. Adherers to appointments were significantly less likely to have a substance misuse disorder and their families were more often involved in treatment. In addition, adherers to medication were significantly less likely to have a substance misuse disorder (9). Another study from
Nigeria that used Morisky medication adherence questionnaire found that $48.0 \%$ of the patients had poor adherence. The significant independent correlates of poor medication adherence included being busy with work, poor social support, high self-stigma and perceived spiritual causation of mental illness (10).

According to the available evidence, nonadherence to psychiatric medications is high and is one of the priority public health problems needing due attention. The findings of the literature showed that about one-half of patients with psychiatric illnesses have poor medication adherence. The literature from different countries, industrialized as well as countries with stunted economy, agrees on that non-adherence is multifactorial in its genesis needing holistic approach and collaborative and integrated efforts at various levels of the society including health sector as well as the public.

However, to the knowledge of the researchers, there is no information in Ethiopia that addresses the magnitude of non-adherence and associated factors among psychiatric patients. Therefore, this study intended to address the magnitude of medication non-adherence among adult psychiatric patients in Jimma University Specialized Hospital located in the southwestern part of the country. The findings of this study could help in generating information related to non-adherence and in designing strategies to solve this problem and to add slight contribution in continuous follow-up of the implemented strategies and related outcome, i.e., decreasing non-adherence to the minimum possible level through time taking realistic measures. Furthermore, this study assessed factors associated with non-adherence and proposed others to find resources that could help in implementing the nonadherence intervention program.

\section{MATERIALS AND METHODS}

A hospital based cross-sectional study was conducted in the psychiatry facility of Jimma University Specialized Hospital (JUSH) found in Jimma Town. Jimma Town is located $350 \mathrm{~km}$ southwest of Addis Ababa, the capital city of Ethiopia. JUSH is a teaching and tertiary level hospital and provides inpatient and outpatient health service for more than 10 million people 
living in southwest of Ethiopia. The hospital gives inpatient services in six clinical departments (Internal medicine, surgery, gynecology and obstetrics, pediatrics, psychiatry and ophthalmology) and outpatient services in the chronic illness follow-up clinics (diabetes, cardiovascular, asthma, epilepsy, tuberculosis and HIV and psychiatry), dermatology, dentistry and other outpatient services (11). During the study period, there were about 2523 outpatients on follow-up at the psychiatry facility. Data collection was conducted in November 2011. A consecutive sample of 422 individuals participated in the study. The sample size was calculated using a single proportion formula by assuming the proportion of non-adherence to be 0.5 (to obtain maximum representative sample size), 5\% margin of error with $95 \%$ confidence interval and $10 \%$ non-response rate. Individuals included in this study were adult psychiatric follow-up patients whose age was $\geq 18$ years and who have visited the psychiatry department at least once before and on prescribed medications. Relatives or other caregivers of people with acute psychosis or inability to respond due to their illness were included in the study. Patients presenting for the first time, individuals who were so seriously ill that they could not respond to the interview and those who did not have family/caregiver, and patients who came for the second time during the study period were excluded from the study.

Data were collected using a pre-tested questionnaire and data-abstracting format adapted from different literatures and modified according to the local context. The questionnaire included five parts that assess patient socio-demographic variables, patient-provider relationship, medication related factors, patient self-reported medication adherence based on the 4 item Morisky Scale and perceived reasons for medication non-adherence. The data-abstracting format was designed to collect data on the number, types and dosing of all prescribed medications, psychiatric related complications and co-morbid conditions from patients' medical records. The questionnaire was translated from English into Afan-Oromo and Amharic languages by native speakers of the languages who are proficient in English and then back-translated into English by other translators to check its consistency in translation.
Medication adherence was measured using the self-reported, 4-item Morisky scale, a commonly used, valid and reliable method (Reliability ranges between 0.61 and 0.83 Cronbach $\alpha$ (12-16). The reliability of Morisky scale in the current study was 0.73 cronbach Alpha. The Morisky scale assesses patients' forgetfulness about taking medications, carelessness about taking medications, stopping medication when feeling better, and stopping medication when feeling worse. Questions were answered as "yes" and "no" and scored one point for "yes" and zero point for "'no" responses. Scores were summed to give total scores, ranging from 0 to 4 . Adherent patients have to score one or below and non-adherence is defined as a score of two or greater (12-16). Patient-provider relationship was assessed using four questions, designed based on the Relationship Scales Questionnaire (RSQ), a valid and reliable instrument. These questions were intended to assess health care providers' communication with the patient about the status of illness, patient participation in decision making of medication choice, counseling on medication and patient satisfaction with the health providers' relationship. Questions are answered as "yes" and "no" and are given scores of 1 for "yes" and 0 for "no" responses. Total score is summed and ranges between 0 and 4 . Scores are interpreted as strong (total score 3 and 4), moderate (total score 2) and weak (total score 0 and 1) relationship between the patient and his/her health care provider (17). Family support/social support was defined as encouraging patients to take medications properly, treatment follow-up, reassurance or listening to the patient talking about his/ her illness, and financial support. Complex drug regimen is a drug regimen which was considered complex if a patient was taking $\geq 3$ drugs with daily dosing of once or more each or patient taking two drugs with daily dosing of two times or more each (18).

Three trained psychologists, who can speak Afan-Oromo and Amharic languages, were selected to collect data through face-to-face interview. Psychiatry nurses did abstracting of clinical data from patient medical records. Data collectors and the supervisor were trained on the study instrument and procedures. The analysis was done using SPSS version16 software. Descriptive statistics was used to analyze the statistical 
association between non-adherence and other independent variables. Then, multiple logistic regression was carried out for variables which showed significant statistical association in the bivariate analysis to control confounding. The strength of association was measured by $95 \%$ confidence level. Goodness of fit of the model was checked using Hosmer and Lemshow and Likelihood ratio test.

The Ethical Committee of the College of Public Health and Medical Sciences, Jimma University, approved this study. In addition, written consent was obtained from each respondent.

\section{RESULTS}

Characteristics and background of the participants: A total of 364(86.3\%) patients and $58(13.7 \%)$ caregivers were participated in the study. Two hundred fifty two, 252(59.7\%), were males. More than half, (55.7\%), of the patients were not married. The majority, (69.7\%), of them were between 20-40 years old with a median age of 28 years. The majorities, $(60 \%)$, of the participants were follower of Islam Religion and Oromo constituted the largest proportion, (63.7\%), of the study subjects. One hundred $(23.7 \%)$ of the total participants could not read and write and they were unemployed. Significant proportions, $(86.6 \%)$, of the patients were living with less than the average household monthly income. The median household monthly income of the respondents was 350 Ethiopian Birr (Table1).

Most, (85.1\%), of the patients lived with their family and around $357(84.6 \%)$ had family or social support both emotionally and financially. Among the total study subjects, 142(33.6\%), $72(17.1 \%)$ and $44(10.4 \%)$ reported having habits of chewing khat (natural stimulant from Catha edulis plant), smoking cigarette and drinking alcohol respectively. In addition, among the total study subjects, 61 (14.5\%) had both khat chewing and smoking habit and 33(7.8\%) had both khat chewing and drinking habits.

Two hundred and ten (49.8\%) of the study participants had equal to or less than a month,
$126(29.9 \%)$ one to three months and $86(20.4 \%)$ three or more months follow-up. Most, (70.6\%), of the participants had regular follow-up practice to their physicians' appointment. The median time needed to reach the psychiatric facility from their residence was 2 hours, with a minimum of 5 minutes and maximum of 4 days. Three hundred and twenty- five $(77 \%)$ of the patients were examined by psychiatry nurses during their follow-up time, $69(16.4 \%)$ of them by mental health postgraduate students and the rest of them by psychiatrists and health officers.

Patient-provider relationship: One hundred forty-five $(34.4 \%)$ of the patients reported good communication with their care providers regarding their status of illness and 120(28.4\%) of them reported having participated in making decision of medication choice. Four hundred and seventeen (98.8\%) of the patients received one or more counseling on their medication (i.e.415(98.3\%), $253(60 \%), 249(59 \%), 91(21.6 \%)$ and 31(7.3\%) patients got medication counseling of timing and dosage, benefit, consequences of missing, possible side effect and time lag before the onset of drug effect respectively). Three hundred and sixty-five (86.5\%) patients had a satisfactory relationship with their care providers. Generally, from the patient-provider relationship scale, two hundred and six (49\%) subjects had a moderate patientprovider relationship while $173(41 \%)$ had strong relationship and $43(10 \%)$ had weak relationship with their care provider.

Diseases and medication related issues: Most, $(41.3 \%)$, of the participants had non-affective psychotic disorder followed by depressive disorder, 125(29.8\%), and bipolar disorder, i.e. 98(23.4\%). The remaining $5.5 \%$ were experiencing anxiety and/or other disorders. Sixtyfour $(15.2 \%)$ of them had lack of insight. Fifty four $(12.8 \%)$ of the patients had some form of comorbidity.

Three hundred and twenty three $(76.5 \%)$ of the total participants reported an experience of one or more medication related side effects, and from the participants 209(49.5\%) patients reported one or more gastro intestinal side effects (Figure 1). 
Table 1: Socio-demographic characteristics with adherence status among adult psychiatric out patients at the psychiatric department of JUSH, southwest Ethiopia, 2011 [N=422].

\begin{tabular}{|c|c|c|c|c|}
\hline \multirow[t]{2}{*}{ Variables } & & \multicolumn{3}{|c|}{ Adherence status } \\
\hline & & $\begin{array}{c}\text { Adherence } \\
\text { № }(\%)\end{array}$ & $\begin{array}{c}\text { Non-adherence } \\
\text { Noo }(\%)\end{array}$ & $\begin{array}{c}\text { Total } \\
\text { № }(\%)\end{array}$ \\
\hline \multirow[t]{2}{*}{ Respondent } & Patient & $213(58.5)$ & $151(41.5)$ & $364(86.3)$ \\
\hline & care giver & $35(60.3)$ & $23(39.7)$ & $58(13.7)$ \\
\hline \multirow[t]{2}{*}{ Gender } & Female & $103(60.6)$ & $67(39.4)$ & $252(59.7)$ \\
\hline & Male & $145(57.5)$ & $107(42.5)$ & $170(40.3)$ \\
\hline \multirow[t]{4}{*}{ Age classification } & $18-20$ & $40(65.6)$ & $21(34.4)$ & $61(14.5)$ \\
\hline & $20-40$ & $171(58.2)$ & $123(41.8)$ & $294(69.7)$ \\
\hline & $40-65$ & $35(55.6)$ & $28(44.4)$ & $63(14.9)$ \\
\hline & $>65$ & $2(50.0)$ & $2(50.0)$ & $4(0.9)$ \\
\hline \multirow[t]{4}{*}{ Religion } & Orthodox & $74(58.3)$ & $53(41.7)$ & $253(60.0)$ \\
\hline & Muslim & $151(59.7)$ & $102(40.3)$ & $127(30.0)$ \\
\hline & Protestant & $20(54.1)$ & $17(45.9)$ & $37(8.8)$ \\
\hline & Catholic & $3(60.0)$ & $2(40.0)$ & $5(1.2)$ \\
\hline \multirow[t]{7}{*}{ Ethnicity } & Oromo & $166(61.7)$ & $103(38.3)$ & $269(63.7)$ \\
\hline & Amhara & $38(55.9)$ & $30(44.1)$ & $68(16.1)$ \\
\hline & Tigray & $9(64.3)$ & $5(35.7)$ & $33(7.8)$ \\
\hline & Gurage & $15(45.5)$ & $18(54.5)$ & $23(5.5)$ \\
\hline & Kefa & $11(47.8)$ & $12(52.2)$ & $14(3.4)$ \\
\hline & Yem & $7(63.6)$ & $4(36.4)$ & $11(2.6)$ \\
\hline & Others & $2(50.0)$ & $2(50.0)$ & $4(0.9)$ \\
\hline \multirow[t]{5}{*}{ Educational status } & Could not read and write & $69(69.0)$ & $31(31.0)$ & $100(23.7)$ \\
\hline & Only read and write & $10(43.5)$ & $13(56.5)$ & $23(5.5)$ \\
\hline & Primary & $78(56.9)$ & $59(43.1)$ & $137(32.5)$ \\
\hline & Secondary & $64(56.6)$ & $49(43.4)$ & $113(26.8)$ \\
\hline & Territory & $27(55.1)$ & $22(44.9)$ & 49 (11.5) \\
\hline \multirow[t]{8}{*}{ Occupation } & Unemployed & $58(58.0)$ & $42(42.0)$ & $100(23.7)$ \\
\hline & House wives & $29(59.2)$ & $20(40.8)$ & $98(23.2)$ \\
\hline & Daily laborer & $15(65.2)$ & $8(34.8)$ & $62(14.7)$ \\
\hline & Governmental employee & $22(50.0)$ & $22(50.0)$ & $49(11.6)$ \\
\hline & Farmer & $60(61.2)$ & $38(38.8)$ & $44(10.4)$ \\
\hline & Merchant & $19(48.7)$ & $20(51.3)$ & $39(9.2)$ \\
\hline & Student & $39(62.9)$ & $23(37.1)$ & $23(5.5)$ \\
\hline & Prisoners & $6(85.7)$ & $1(14.3)$ & $7(1.5)$ \\
\hline \multirow{6}{*}{$\begin{array}{l}\text { Household Monthly } \\
\text { income } \\
\text { Marital status }\end{array}$} & Below average & $210(60.2)$ & $139(39.8)$ & $349(86.6)$ \\
\hline & Above average & $27(50.0)$ & $27(50.0)$ & $54(13.4)$ \\
\hline & Single & $136(57.9)$ & $99(42.1)$ & $235(55.7)$ \\
\hline & Married & $91(61.5)$ & $57(38.5)$ & $148(35.1)$ \\
\hline & Divorced & $13(44.8)$ & $16(55.2)$ & $29(6.9)$ \\
\hline & Widowed & $8(80.0)$ & $2(20.0)$ & $10(2.3)$ \\
\hline
\end{tabular}




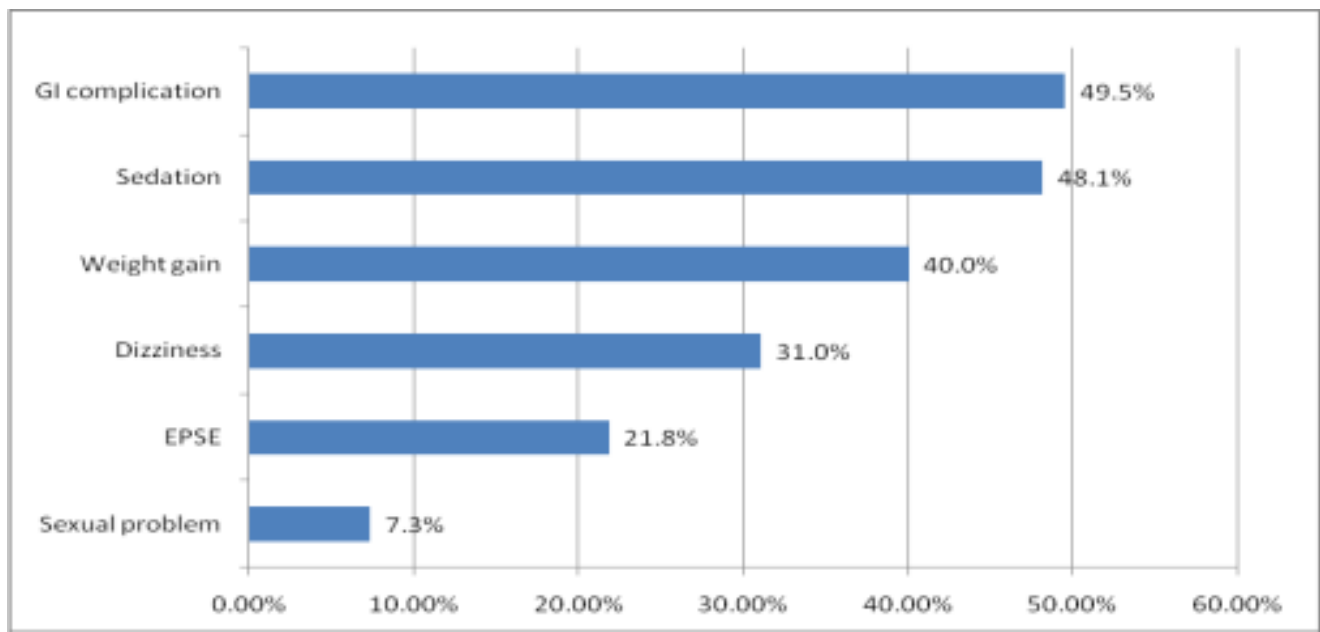

*EPSE: Extra pyramidal side effects

Figure 1: Frequency of perceived side effects among adult psychiatric out patients at the psychiatric department of JUSH, Southwest Ethiopia 2011 [N=422].

Three hundred and thirty-two (78.7\%) patients administered medication by themselves while $90(21.3 \%)$ of them got it done by their care givers. The median total duration of treatment for the patients' was three years and the range was from one week to thirty years. The highest numbers of prescribed medications to the participants were antipsychotic medications 161(38.2\%) (Table2).

Table 2: Prescribed drug type with adherence status among adult psychiatric out patients at the psychiatric department of JUSH, southwest Ethiopia, 2011.

\begin{tabular}{llll}
\hline Prescribed drugs & \multicolumn{2}{c}{ Adherence status } & Total [No (\%)] \\
\cline { 2 - 3 } & Adherent [No (\%)] & Non-adherent [No(\%)] & \\
Antipsychotic & $103(64.0)$ & $58(36.0)$ & $161(38.2)$ \\
Antidepressant & $36(54.5)$ & $30(45.5)$ & $66(15.7)$ \\
Mood stabilizer & $16(64.0)$ & $9(36.0)$ & $25(5.9)$ \\
Antipsychotic + Antidepressant & $48(57.1)$ & $36(42.9)$ & $84(19.9)$ \\
Antipsychotic + Mood stabilizer & $35(53.0)$ & $31(47.0)$ & $66(15.6)$ \\
Other drugs & $10(50.0)$ & $10(50.0)$ & $20(4.7)$ \\
Total & $248(58.8)$ & $174(41.2)$ & $422(100.0)$ \\
\hline
\end{tabular}

Patients with anti-psychotic medication (33.3\%) had the high prevalence of non-adherence rate. One hundred $(23.7 \%)$ patients had complex drug regimen in their treatment.

Adherence status and reasons for nonadherence: One hundred and seventy four
(41.2\%) of the patients were non-adherent to medications prescribed by their health care providers. For non-adherent patients, the commonest reported reasons were forgetting $136(78.2 \%)$ and feeling better 77(44.3\%) (Figure 2). 


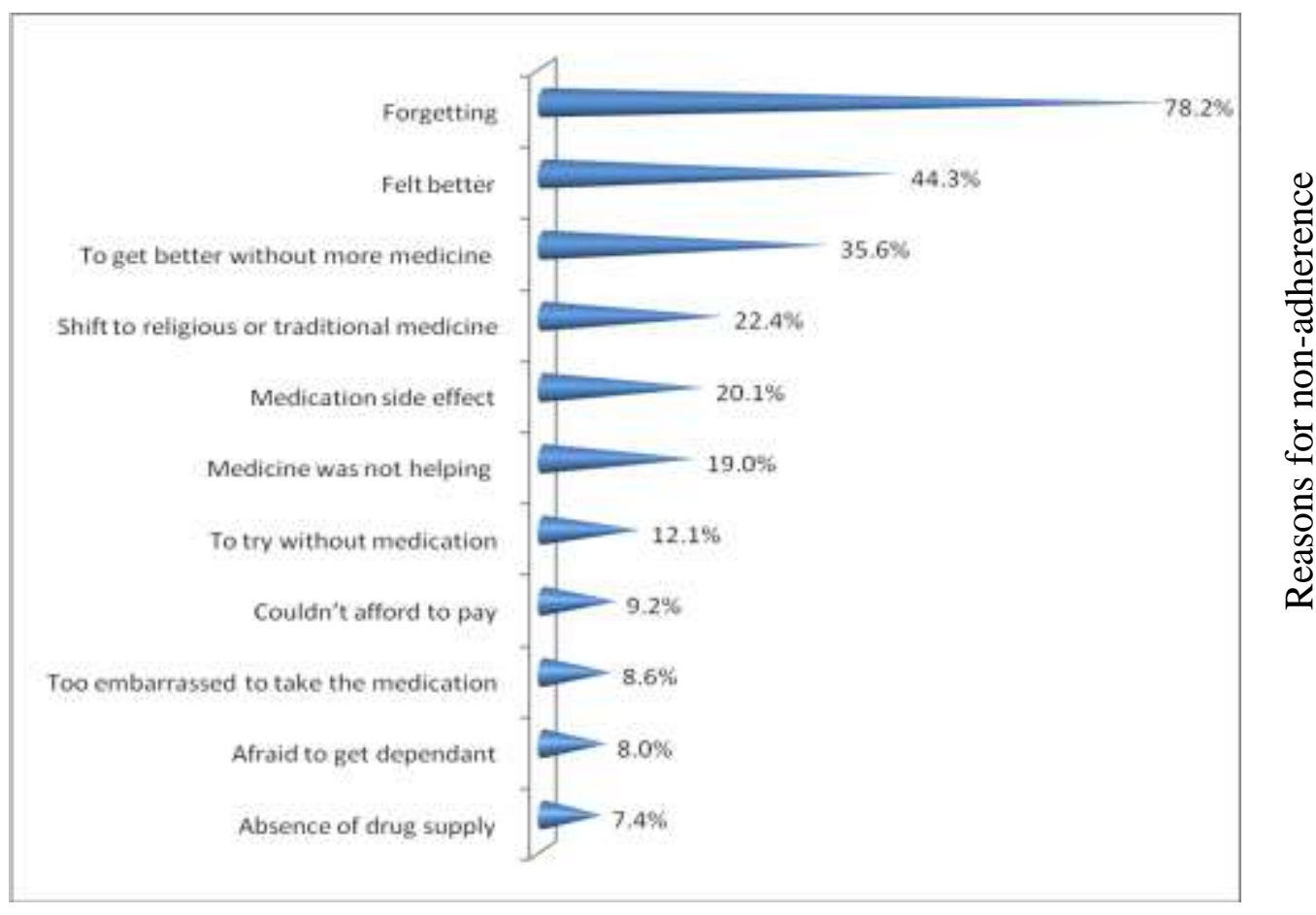

Percentage of reasons for non-adherence

Figure 2: Reasons for non-adherence among adult psychiatric out patients at the psychiatric department of JUSH, Southwest Ethiopia, 2011 [N=174].

Determinants of medications non-adherence: Results from the multiple logistic regression analysis indicated that irregular follow-up, lack of family/social support and a complex drug regimen were the predictors of medication non-adherence. The goodness of fit of the model was checked by Hosmer and Lemshow test and Likely Hood Ratio test and was found as fit. In addition, two-way interactions between variables were tested and interaction between variables were not found. The odds of non-adherence among patients who lacked regular follow-up were 2 times more than those of those who do not [AOR-2.0, 95\%CI $(1.21,3.29)]$. Poor family/social support was associated with increasing risk of non-adherence [AOR- 2.1, 95\%CI $(1.03,4.18)]$. Patients who had complex prescribed drug regimen were more likely to be [AOR- 2.1, 95\%CI $(1.19,3.63)]$ non-adherent to their medication than those without complex drug regimen (Table 3 ).

\section{DISCUSSION}

In this study, among the 422 psychiatric patients, $41.2 \%$ were non-adherent to medication. The most common reasons for non-adherence were forgetting to take medication and feeling better or healthy. Irregular follow-up, lack of family/social support and complex drug regimen were also factors associated with non-adherence.

The level of non-adherence found in the study was lower than findings reported in Nigeria (9, 10). Such differences might be related to differences in the methodology used to assess medication non-adherence-the current scale is not validated in Ethiopia and in this study the majority of the patients had family/social support. However, the non-adherence rate in the present study was found to be slightly higher in comparison with the report from Pakistan (8). It might be due to the differences in health care setting or the level of training differences on drug adherence for health providers. In addition, the participants of this study had low household income and patients traveled longer distances to psychiatric facility. It may be also due to the difficult topographic and inconvenient mode of transportation to get care and the lack of awareness about mental illness in our study. 
Table 3: Multiple logistic regression showing predictors of medication non-adherence among JUSH adult psychiatric patients in South west Ethiopia, 2011.

\begin{tabular}{|c|c|c|c|c|}
\hline \multirow[b]{2}{*}{ Variables } & & \multicolumn{2}{|c|}{ Adherence status } & \multirow[b]{2}{*}{$\operatorname{AOR}(95 \%$ C.I) } \\
\hline & & $\begin{array}{l}\text { Non adherent } \\
\text { oㅡ }(\%)\end{array}$ & $\begin{array}{l}\text { Adherent } \\
\text { No }(\%)\end{array}$ & \\
\hline Lack of family/ Social support & Yes & $36(55.4)$ & $29(44.6)$ & $* * 2.1 \quad(1.031,4.182)$ \\
\hline $\begin{array}{l}\text { Counseling on time lag before onset of drug } \\
\text { effect }\end{array}$ & $\begin{array}{l}\text { No } \\
\text { Yes }\end{array}$ & $\begin{array}{l}138(38.7) \\
19(61.3)\end{array}$ & $\begin{array}{l}219(61.3) \\
12(38.7)\end{array}$ & $\begin{array}{l}1.00 \\
1.00\end{array}$ \\
\hline Irregular follow up & $\begin{array}{l}\text { No } \\
\text { Yes }\end{array}$ & $\begin{array}{l}155(39.6) \\
72(58.1)\end{array}$ & $\begin{array}{l}236(60.4) \\
52(41.9)\end{array}$ & $\begin{array}{l}2.1 \quad(0.832,5.178) \\
* * 2.0(1.209,3.289)\end{array}$ \\
\hline EPSE & $\begin{array}{l}\text { No } \\
\text { Yes } \\
\text { No } \\
\text { Yes }\end{array}$ & $\begin{array}{l}102(34.2) \\
52(56.5) \\
99(42.5) \\
20(64.5)\end{array}$ & $\begin{array}{l}196(65.8) \\
40(43.5) \\
134(57.5) \\
11(35.5)\end{array}$ & $\begin{array}{l}1.00 \\
1.5(0.878,2.52) \\
1.00 \\
1.7(0.738 .3 .977)\end{array}$ \\
\hline Sexual problem & No & 131(44.6) & $163(55.4)$ & 1.00 \\
\hline Co morbid & $\begin{array}{l}\text { Yes } \\
\text { No }\end{array}$ & $\begin{array}{l}30(55.6) \\
144(39.1)\end{array}$ & $\begin{array}{l}24(44.4) \\
224(60.9)\end{array}$ & $\begin{array}{l}2.0(0.968,4.028) \\
1.00\end{array}$ \\
\hline Complex drug regimen & $\begin{array}{l}\text { Yes } \\
\text { No }\end{array}$ & $\begin{array}{l}51(51.0) \\
123(38.2)\end{array}$ & $\begin{array}{l}49(49.0) \\
199(61.8)\end{array}$ & $\begin{array}{l}* * 2.1 \quad(1.192,3.626) \\
1.00\end{array}$ \\
\hline \multirow[t]{5}{*}{ Duration of treatment } & $<1$ year & $45(33.3)$ & $90(66.7)$ & 1.00 \\
\hline & $\begin{array}{l}1-2 \\
\text { years }\end{array}$ & $24(43.6)$ & $31(56.4)$ & $0.5(0.208,1.317)$ \\
\hline & $\begin{array}{l}2-5 \\
\text { years }\end{array}$ & $45(42.9)$ & $60(57.1)$ & $0.9(0.302,2.433)$ \\
\hline & $\begin{array}{l}5-10 \\
\text { years }\end{array}$ & $42(45.7)$ & $50(54.3)$ & $0.7(0.285,1.823)$ \\
\hline & $\begin{array}{l}10 \text { and } \\
\text { above }\end{array}$ & $18(51.4)$ & 17(48.6) & $1.0(0.412,2.681)$ \\
\hline
\end{tabular}

** Statistically significant at $\mathrm{P}$-value $<0.05$

Patients suffering from psychotic disorders were more non-adherent in this study which is similar with a previous study done in Pakistan (8). However, the non-adherence of patients with bipolar disorder was increased by $16 \%$ in the current study and it could be related to greater probability of combination of medications prescribed for bipolar patients.

In the present study, forgetting to take medications and feeling better were the most common reported reasons for non-adherence. These two reasons were also reported to be the major reasons for non-adherence in Canada, India and Pakistan $(5,7,8)$. But stopping medication because of feeling better was found to be much higher in comparison with the finding of a study done in India (7). Such difference may be related to lack of awareness about long term medication. However, difficulty to obtain drugs because of financial problem was found much lower in the current study compared to the result reported in India (7) and Pakistan (8). Regarding the cost, most of the patients in this study setup had the opportunity to get medications free of charge from the hospital. Another reason for non-adherence in this study was shifting to religious or traditional medicine. This may be due to inadequate communication to patients on their illness status. The non-adherent patients reported that health care providers also had failed to adequately explain the time lag before onset of treatment response, benefit of prescription, possible side effects, and consequence of non-adherence. This result is also similar with the finding in Pakistan (8). 
Non-adherence was higher among patients who were prescribed both anti psychotic and mood stabilizer medications followed by antidepressant medications than other medication types. These findings are supported by the study reported in Canada (6). These may suggest that the combination of drug prescription may be one factor for non-adherence. The reasons for the increased non-adherence of antidepressant medication-taking patients may also need further investigation.

The prevalence of non-adherence among patients administering their medication by themselves and those whose medications were administered by their family/caregiver was almost the same. This result differs from a finding in Pakistan where patients taking their medication on their own were more adherent than patients who were taking their medication under family/caregiver follow-up. This could be that the family remains an important resource for the support and care of psychiatric patients in most African countries (9). In addition, poor family/social supports were significantly associated with medication non-adherence. A study from Nigeria also indicated that poor family/social support was significantly associated with poor adherence rate (10). This can be because of the family serving as a cue to action or reinforcing factor for drug adherence for psychiatric patients.

Participants who had irregular follow-up in this study were strongly associated with medication non-adherence and this is similar with study done in Nigeria (9). Regular follow-up may increase the exposure for reminder from health care providers since those with regular follow-up may have better knowledge about the benefits of medication adherence. Complex drug regimen was also a predictor for non-adherence. Psychotropic medications have a well-demonstrated and documented number of side effects (19). Hence, as the complexity of the drugs increases the side effects may increase resulting in increased risk of non-adherence.

There are a few limitations in this study. Firstly, the reported non-adherence could be an underestimate of the reality as there may be a recall bias associated with self-reporting of medication adherence. It may also affected by social desirability bias as the setting of data collection was the psychiatric outpatient department and the data collectors were staff members of the hospital. Secondly, cause-effect relationships cannot be established because of cross-sectional nature of the study design. Nevertheless, the finding adds valuable information to our understanding the of magnitude and potential factors affecting adherence to psychotropic medications in sub-Saharan African setting.

In conclusion, in this study, the prevalence of non-adherence to psychiatric medications was found to be high. The most common reasons for non-adherence in this study were forgetting to take medications and feeling healthy. Patients with low social support, patients who did not have regular follow-up and those who were on complex drug regimen were more likely to be non-adherent for prescribed medications. Making medication regimen as simple as possible by health care professionals at psychiatric facilities may decrease the non-adherence rate for psychiatric medications. In addition, a strategy at improving regular follow-up system and promoting social support is necessary for minimizing medication non-adherence among psychiatric patients. Further studies are also required on the quality and dimensions of doctor-patient relationship at the psychiatric facility and its impact on nonadherence. As forgetting was mentioned as one of the leading reasons of non-adherence, it should be explored why patients forget to take their medications in another study.

\section{ACKNOWLEDGMENT}

We would like to thank the participants of the study, data collectors, supervisors, and department of Psychiatry for the cooperation and assistance and Jimma University in general for financing this study.

\section{REFERENCES}

1. Cramer A, Rosenheck R: Compliance with medication regimens for mental and physical disorders. Psychiatry Serve 1998, 49:196201.

2. Debbie R: medication management in review the Australian journal of pharmacy 2007, vol.88 October 
3. Morris S, Schulz M: Patient compliance--an overview.J Clin Pharm Ther1992, 17: 28395.

4. Zygmunt A, Olfson M, Boyer A, Mechanic D: Interventions to improve medication adherence in schizophrenia. Am J Psychiatry 2002; 159: 1653-64.

5. Lacro P, Dunn B, Dolder R, leckband G, Jeste V: Prevalence of and risk for medication adherence in patients with schizophrenia a comprehensive review of recent literature. j clin psychiatry. 2002,63; 892-909.

6. Andrew M, Bulloch E, Scott B: Patten,Nonadherence with psychotropic medications in the general Population Springer-Verlag, 2009.

7. Rekha R, Masroor J, Sushma K, Prashant K, Chakraborty: Reasons for Drug NonCompliance of Psychiatric Patients:A Centre Based Study,2003.

8. Fawad T, Mansoor T: Factors associated with Non-adherence among Psychiatric patients at a Tertiary Care Hospital, Karachi, Pakistan: J Pak Med Assoc August 2008, Vol. 58, No. 8.

9. Ademola B, Adeponle: Family participation in treatment, post-discharge appointment and medication adherence at a Nigerian psychiatric hospital, The British Journal of Psychiatry 2009, 194, 86-87.

10. Abiodun O, Adewuya, Olugbenga A: Prevalence and correlates of poor medication adherence amongst psychiatric outpatients in southwestern Nigeria: General Hospital Psychiatry: March 2009,Volume 31, Issue 2 , Pages 167-174.

11. Worku, D, Hamza L, Woldemichael, K: Patterns of diabetes complications at Jimma University specialized hospital, southwest Ethiopia. Ethiop. J. Health Sci 2010, 20, 3339.
12. John A. Bates, PhD, Richard Whitehead, BS, Susan C. Bolge, PhD, and Edward Kim, MD, MBA : Correlates of Medication Adherence Among Patients With Bipolar Disorder: Results of the Bipolar Evaluation of Satisfaction and Tolerability (BEST) Study: A Nationwide Cross-Sectional Survey.Prim Care Companion J Clin Psychiatry. 2010; 12(5).

13. Rigby, D: Adherence assessment tools: Drugs don't work when they are not taken. Aus. J. Pharm 2007,88, 32-33.

14. Shelly A, Vik C, Maxwell J: Assessing medication adherence among older persons in community settings Can J Clin Pharmacol 2005, Vol 12 (1).

15. Morisky .E, Green W, Levine M: Concurrent and predictive validity of self-reported measures of medication adherence. Med. Care 1986, 24, 67-74.

16. Donald E, Morisky D, Alfonso A: Predictive validity of A medication adherence measure in an Outpatient Setting: J Clin Hypertens (Greenwich). 2008 May,10(5): 348-354.

17. Ciechanowski S, Katon J, Russo E, Walker A: The patient-provider relationship: attachment theory and adherence to treatment in diabetes. Am. J. Psychiatry 2001,158, 2935.

18. Teferra A, Alemayehu W: Patient non compliance with drug regimens for chronic diseases in North West Ethiopia, Ethiop.J.Health dev.2000.

19. Stephen S: Essential psychopharmacology: neuroscientific basis and practical application; with illustrations by Nancy Muntner, San Diego: Cambridge University Press-2nd ed.2000. 